\title{
Rapid Microwave Synthesis of $\beta$-SnWO4 Nanoparticles: An Efficient Anode Material for Lithium-Ion Batteries
}

\section{Sumedha $\mathbf{N}$}

Tumkur University

Mabkhoot Alsaiari

Najran University

Mohammed Jalalah

Najran University

\section{Shashank M}

Tumkur University

Fahad Alharthi ( $\nabla$ fharthi@ksu.edu.sa )

King Saud University

Naushad Ahmad

King Saud University

Jari Algethami

Najran University

Vishwantha R

Jyothi Institute of Technology, Bangalore, Karnataka

Nagaraju Ganganagappa

Tumkur University

\section{Research Article}

Keywords: galvanometric, crystalline nature, nanoparticles, stoichiometric ratio

Posted Date: December 4th, 2020

DOl: https://doi.org/10.21203/rs.3.rs-113681/v1

License: (c) (i) This work is licensed under a Creative Commons Attribution 4.0 International License.

Read Full License 


\section{Rapid Microwave Synthesis of $\beta-\mathrm{SnWO}_{4}$ Nanoparticles: An Efficient Anode Material}

\section{for Lithium-ion Batteries}

\section{Sumedha H N ${ }^{\mathrm{a}}$, Mabkhoot A. Alsaiari ${ }^{\mathrm{b}, \mathrm{c}}$, Mohammed S. Jalalah ${ }^{\mathrm{b}, \mathrm{d}}$, Shashank $\mathbf{M}^{\mathrm{a}, \mathrm{e}}$, Fahad A. Alharthi ${ }^{\mathrm{f} *}$, Naushad Ahmad ${ }^{\mathrm{f}}$, Jari S. Algethamic, Vishwantha $\mathbf{R}^{\mathrm{g}}$, Nagaraju Ganganagappa $^{\mathrm{a} *}$ \\ ${ }^{a}$ Energy Materials Research Laboratory, Department of Chemistry, Siddaganga Institute of Technology, Tumakuru - 572103, Karnataka, India \\ ${ }^{b}$ Promising Center for $S$ and Electronic Devices (PCSED), Advanced Materials and Nano \\ Research Center, Najran University, P. O. BOX: 1988, Najran 11001, Saudi Arabia \\ ${ }^{c}$ Chemistry Department, Faculty of Science and Art at Sharurah, Najran University, Saudi Arabia \\ ${ }^{d}$ Department of Electrical Engineering, Faculty of Engineering, Najran University, Saudi Arabia. \\ ${ }^{e}$ Department of Studies and Research in Industrial Chemistry School of Chemical Sciences, Kuvempu University, Shankaragatta-577451, India \\ ${ }^{f}$ Department of Chemistry, College of Science, King Saud University, P.O. 2455, Riyadh 11451, Saudi Arabia \\ ${ }^{g}$ Department of Chemistry, Jyothi Institute of Technology, Bangalore, Karnataka, India}

\footnotetext{
**Corresponding author: fharthi@ksu.edu.sa_nagarajugn@sit.ac.in
} 


\section{Abstract}

Here, we report a facile synthesis of $\beta-\mathrm{SnWO}_{4}$ nanoparticles via microwave heat treatment using $\mathrm{SnCl}_{2}$ and $\mathrm{H}_{2} \mathrm{WO}_{4}$, in the presence of tamarind seed powder. X-ray diffraction analysis confirmed the crystalline nature, revealing a cubic structure of $\beta-\mathrm{SnWO}_{4}$ nanoparticles. Morphological features were visualized using a scanning electron microscope which exhibited homogenously distributed clusters of nanoparticles which were further confirmed using transmission electron microscope. The micrographs also displayed some porosity. Energy dispersive X-ray spectroscopy confirmed the elemental contents such as tin, oxygen and tungsten in the same stoichiometric ratio as expected by the respective empirical formula. High-resolution transmission electron microscope was used to find the d-spacing which was ultimately used to analyze the structural parameters. The spectrum obtained using Fourier transform infrared spectroscopy illuminates different stretching vibrations. Additionally, Barrett-Joyner-Halenda analysis was carried out to investigate $\mathrm{N}_{2}$ adsorption-desorption isotherm as well as to govern the pore size distribution. Cyclic voltammetry measurements were implemented to analyze the ongoing electrode reactions throughout the charge/discharge for $\beta-\mathrm{SnWO}_{4}$ nanostructures. The galvanometric charge/discharge curves for $\beta-\mathrm{SnWO}_{4}$ have also been discussed. A high specific capacitance (600 mAhg ${ }^{-1}$ at $\left.0.1 \mathrm{C}\right)$ and excellent columbic efficiency ( 100\%) was achieved.

\section{Introduction}

The demand of energy storage devices with enhanced capabilities has increased manifold in the $21^{\text {st }}$ century. In this context, the researchers world-wide are looking for such devices and materials that might lead the scientific community to cope up with the energy storage needs by 
designing and developing innovative resources. In the current era, energy renovation is the forefront of research [1]. Lithium ion batteries (LIBs) are considered as promising because of their high power density, life cycle, gravimetric and volumetric energy along with long self-discharge properties. Therefore, the LIBs are still unbeaten in energy storage industry [2]. Meanwhile, the earth's crust has limited availability of lithium resources and their use is beyond the limits, consequently, they are becoming costly [3, 4]. Alternatively, batteries are facing various problems including storage capacity and chemical stability [5]. Additionally, its specific capacity is extremely low i.e., $372 \mathrm{mAhg}^{-1}$. To resolve such issues, there is a need to investigate some favorable electrode materials exhibiting promising specific capacities and chemical stabilities. In the realm of rechargeable LIBs, various nanomaterials are under discussion as a potential electrode material.

Historically, the LIBs have shown a massive intensification through the two decades in specific energy values ranging from 90 to $250 \mathrm{mAhg}^{-1}$ [6]. In this regime, there are a lot of breakthroughs in energy storage devices due to the advancement in the field of nanomaterials [79]. The nanomaterials have exceptionally attractive physical and chemical properties; hence they are reflected suitable for energy storage devices. The use of single metal oxides including $\mathrm{TiO}_{2}$ [10], $\mathrm{SnO}_{2}$ [11] and $\mathrm{Ta}_{2} \mathrm{O}_{5}$ [12] has led to the loss in capacity with cycling. Whereas, the literature survey reveals good electrochemical performance of $\beta-\mathrm{SnWO}_{4}$ nanoparticles. Various routes have been adopted for the synthesis of $\mathrm{SnWO}_{4}$ including hydrothermal synthesis [13], combustion method and microwave method [14]. Initially, the gas sensing properties as well as the phasestructure of $\alpha$ - and $\beta-\mathrm{SnWO}_{4}$ was reported by Solis and Lantoo by employing different spectroscopic techniques $[15,16]$. Ede et al. adopted microwave synthesis to prepare $\mathrm{SnWO}_{4}[16]$. Warmuth et al., employed microwave assisted method to synthesize $\beta-\mathrm{SnWO}_{4}$ nanoparticles [17]. 
Furthermore, the photoelectrochemical properties of $\beta-\mathrm{SnWO}_{4}$ nanomaterials were analyzed by Cho et al. [18]. $\mathrm{ZnWO}_{4}$ nanocrystals/reduced graphene oxide hybrids were prepared by Wang Xiao et al. via facile hydrothermal route which revealed a performance of $477 \mathrm{mAhg}^{-1}$ after 40 cycles [19]. Whereas, $\alpha-\mathrm{SnWO}_{4} /$ reduced graphene oxide nanoparticles were synthesized by Renkun Huang et al. through facile single step hydrothermal reaction exhibiting a capacity of 500 $\mathrm{mAhg}^{-1}$ after 20 cycles [20].

The search of the finest electrode material for LIBs having high capacity and that can easily be diffused into $\mathrm{Li}^{+}$ions along with increased life cycle is still under investigation. Owing to the promising features associated with $\beta-\mathrm{SnWO}_{4}$ nanoparticles, here we report a facile synthesis of this material and present a detailed analysis of its electrochemical performance for its potential use as an electrode material in LIBs.

\section{Experimental}

\subsection{Synthesis of $\beta-\mathrm{SnWO}_{4}$ nanoparticles}

$\beta-\mathrm{SnWO}_{4}$ nanoparticles were prepared through rapid microwave heat treatment by the reaction of $\mathrm{SnCl}_{2}$ and $\mathrm{H}_{2} \mathrm{WO}_{4}$ in the presence of tamarind seed powder. A typical procedure involves the addition of $220 \mathrm{mg}$ of $\mathrm{SnCl}_{2}, 249 \mathrm{mg}$ of $\mathrm{H}_{2} \mathrm{WO}_{4}$ in a clean and dried crucible. In the meantime, $220 \mathrm{mg}$ of tamarind seed powder was also added followed by the addition of $10 \mathrm{~mL}$ of distilled water. The obtained blend was stirred for about $10 \mathrm{~min}$. At that time, the crucible was kept in a microwave oven at $900 \mathrm{~W}$ for $5 \mathrm{~min}$. The resultant product was taken out from the oven and allows it to cool to room temperature naturally. Later, it was grinded in a clean dried mortar and calcined at $700{ }^{\circ} \mathrm{C}$ for $4 \mathrm{~h}$ under static air. The schematic of sample synthesis is presented in Figure 1.

\subsection{Characterization}


A Rigaku's Smart Lab, X-ray diffractometer (XRD) with Cu- $K_{\alpha}$ radiations $(\lambda=1.5406 \AA)$ was used to determine the crystalline nature and confirmation of phase. Molecular vibrations and structures of the materials were analyzed from $350-4000 \mathrm{~cm}^{-1}$ using Bruker Alpha-P Fourier transforms infrared (FTIR) spectrometer by KBr pellet method. JEOL- JCM-6000 Plus scanning electron microscopy (SEM) and a JEOL, JEM-2100 transmission electron microscopy (TEM) were utilized to observe the morphological features, particle size and structural parameters of $\beta$ SnWO4 nanoparticles, respectively. Using Quanta chrome Nova 2200E - BET (surface area analyzer), the pore size and surface area was determined.

\subsection{Electrode fabrication for Lithium ion battery}

A coin cell was made to examine the electrochemical performance of $\beta-\mathrm{SnWO}_{4}$ nanomaterials by fabricating it on a copper foil. The slurry was prepared by mixing the active materials $\left(\beta-\mathrm{SnWO}_{4}\right.$ nanoparticles), PVDF (polyvinylidene fluoride) and acetylene black using a weight ratio of 80:5:15, respectively using few drops of N-Methyl pyrrolidine as a solvent. The prepared slurry was uniformly coated on a $\mathrm{Cu}$ foil and subsequently dried at $100{ }^{\circ} \mathrm{C}$ for $12 \mathrm{~h}$, in a vacuum oven. During the coil cell fabrication, polypropylene membrane (Celgard-2400) was utilized as a separator. LiPF6 (1M) dissolved in ethylene carbonate, dimethyl carbonate and diethyl carbonate (2: 2: 1) was used as an electrolyte. Cyclic voltametry (CV) and galvanostatic charge-discharge (GCD) studies were recorded using a Bio-logic BCS 805 battery system. The CV measurements were performed in the voltage window from 0.01 to $3 \mathrm{~V}$ at $50 \mathrm{mV} / \mathrm{s}$ scan rate. The voltage range of 0.01-3 V was also applied during the GCD analysis.

\section{Results and discussion}

The XRD pattern of the sample was recorded in the $2 \theta$ range of $15-70^{\circ}$, as shown in Figure 2(a). The existence of intensity peaks corresponding to the (200), (020), (001), (100, (-112), (202), 
(411), (222), (112), (212), (211), (322), (820) and (811) planes was perfectly matched with JCPDS (Joint Committee on Powder Diffraction Standards) reference no. 01-070-1497 [16], a characteristic reference pattern of $\beta-\mathrm{SnWO}_{4}$. It confirmed the wolframite type cubic crystal structure of the sample, having space group no. 198 and a space group category P-213 [21]. There was not any extra peak signifying the phase purity of sample [16]. Further, the magnified image of some peaks is illustrated in Figure 2(b) to differentiate between these peaks. The lattice parameter (a) was calculated from following equation;

$$
a=\frac{\lambda \sqrt{h^{2}+k^{2}+l^{2}}}{2 \sin \theta_{B}}
$$

The lattice parameter was measured to be $a=b=c=7.298 \AA$, resulting into a unit cell volume of $388.697 \AA^{3}$. The average crystallite size $\left(D_{h k l}\right)$ was determined using Scherrer's formula as described by Eq. 2 [22];

$$
D=\frac{k \lambda}{\beta \cos \theta_{B}}
$$

Where, $\beta$ is line broadening termed as full width at half maximum (FWHM), $\theta_{B}$ represents the Bragg's angle, $\lambda$ is wavelength with a value of $1.54 \AA$ and $k=0.9$, the shape factor. The crystallite size as evaluated by this formula was $28.63 \mathrm{~nm}$.

The crystallite size of as-synthesized samples was also calculated using Williamson-Hall (W-H) method as given by Eq. 3 [23];

$$
\beta \cos \theta=k \lambda / D+4 \varepsilon \sin \theta
$$

Where, $\varepsilon$ is representing the lattice strain. Figure 3 indicates the $\mathrm{W}-\mathrm{H}$ plot of $\beta-\mathrm{SnWO}_{4}$ plotted between $4 \sin \theta$ at $x$-axis and $\beta \cos \theta$ along the $y$-axis. The $D$ is measured from the $y$-intercept and depicted to be $24.32 \mathrm{~nm}$ while $\varepsilon$ measures slope of the linear fit and is measured to be $7.2 \times 10^{-2}$. The linear fit of $\mathrm{W}-\mathrm{H}$ plot is expected to be a straight line parallel to $x$-axis but in the manifestation 
of $\varepsilon$ it gives a non-zero slope [26]. The measured crystallite size $(24.32 \mathrm{~nm})$ from $\mathrm{W}-\mathrm{H}$ plot was in close agreement with Scherrer's formula $(28.63 \mathrm{~nm})$.

The accurate phase analysis and quantitative phase measurement of $\beta-\mathrm{SnWO}_{4}$ was determined through Rietveld refinement analysis via X'pert HighScore Plus software. Figure shows the well fitted XRD pattern of $\beta-\mathrm{SnWO}_{4}$ at the same positions as prescribed in Figure 4. No significant phase transformation was perceived attributing pure phase formation of the specimen. The structural reliability was evaluated by measuring R-factors such as R-profile $\left(R_{p}\right)$, R-expected $\left(R_{\text {exp }}\right), \mathrm{R}$-profile $\left(R_{w p}\right)$ and R-Bragg $\left(R_{B}\right)$ as well through the following Eqs. 4 -7 [25].

$$
\begin{gathered}
R_{w p}=\left[\frac{\Sigma_{i} w_{i}\left(I_{C}-I_{0}\right)}{\Sigma_{i} w_{i} I_{0}^{2}}\right]^{1 / 2} \\
R_{\text {exp }}=\left[\frac{N-P}{\Sigma_{i} w_{i} I_{0}^{2}}\right]^{1 / 2} \\
R_{\text {Bragg }}=\frac{\Sigma|I(0)-I(c)|}{\Sigma|I(0)|} \\
R_{p}=\frac{\Sigma\left|I\left(0_{i}\right)-I\left(c_{i}\right)\right|}{\Sigma\left|I\left(0_{i}\right)\right|}
\end{gathered}
$$

Here, $P$ and $N$ represent number of refined parameters and number of experimentally observed points and $I_{o}$ and $I_{c}$ present the observed and calculated integrated intensities, respectively. Accordingly, $w_{i}$ is illustrating weight factor at $i$ point of diffraction profile and goodness of fit $\left(\chi^{2}\right)$ was measured using Eq. 8, given as [25];

$$
\chi^{2}=\frac{R_{w p}}{R_{\exp }}
$$

The measured parameters from Rietveld refinement analysis are summarized in Table 1. The obtained smaller value of $\chi^{2}$ is depicting the pure phase development of $\beta-\mathrm{SnWO}_{4}$.

The SEM images for $\beta-\mathrm{SnWO}_{4}$ are illustrated in Figure $5(\mathrm{a}-\mathrm{c})$. The micrographs are obtained at diverse magnifications revealing the formation of $\beta-\mathrm{SnWO}_{4}$ nanoclusters along with 
some sorts of layered and rough structure as well. Stone like arbitrary and amalgamated particles of various sizes and shapes could be perceived in the micrographs. Figure 5(b-c) is illustrating some rock like structures along with very small particles. Furthermore, the images also reveal the porosity present in the sample.

The EDX spectrum of $\beta-\mathrm{SnWO}_{4}$ has been profiled in Figure 5(d). It confirmed the existence of all the constituent elements such as tin, oxygen and tungsten in the sample. The table shown in an inset of Figure 5(d) is demonstrating the mass percentages of all the elements.

The morphology of $\beta-\mathrm{SnWO}_{4}$ was also examined using TEM and HR-TEM to get detailed breakdown about structure and to determine the interlayer $d$-spacing. Figure 6(a-b) is illustrating TEM images obtained at different magnifications. The micrographs are profiling almost spherical shaped particles accompanied by some amalgamation. Further, some pores could also be professed in the micrographs. The interlayer $d$-spacing was examined through HR-TEM and found to be 0.33 $\mathrm{nm}$ [26] that could be perceived in Figure 6(c). The lattice fringes of (001) lattice plane of wolframite type cubic crystal structure $\beta-\mathrm{SnWO}_{4}$ could be perceived in Figure 5(d) as sketched by selected area electron diffraction (SEAD) pattern. The occurrences of bright rings in the concerning pattern is illustrating the company of highly crystallite particles. The existence of lattice plane is in good agreement with XRD pattern.

The FTIR spectrum for $\beta-\mathrm{SnWO}_{4}$ was recorded in the range of $350-4000$ and $\mathrm{cm}^{-1}$ is shown in Figure 7. The peak appearing around $609 \mathrm{~cm}^{-1}$ is demonstrating asymmetric stretching vibration of $\mathrm{W}_{6}^{-6}$ group [26, 27]. In the same way, the peaks emerging at 768 and $851 \mathrm{~cm}^{-1}$ are illuminating stretching vibrations of $\mathrm{W}-\mathrm{W}$ and $\mathrm{W}-\mathrm{O}-\mathrm{W}$ bridging bonds [27]. The structural vibrations of $\mathrm{C}-\mathrm{C}$ or $\mathrm{C}-\mathrm{O}-\mathrm{C}$ bonds are in well agreement with the peak occurring at $1443 \mathrm{~cm}^{-1}$. Further, the existence 
of a strong peak at $1640 \mathrm{~cm}^{-1}$ and a broad peak at 3421 corresponds to stretching and bending vibrations of hydroxyl $(-\mathrm{OH})$ group. The symmetric stretching vibration of $\mathrm{C}-\mathrm{H}$ bond can be observed from peak befalling at $2921 \mathrm{~cm}^{-1}$. The co-existence of all the stretching and vibrational peaks confirmed the formation of $\beta-\mathrm{SnWO}_{4}$ structure [28].

Barrett-Joyner-Halenda (BJH) analysis was carried out to investigate $\mathrm{N}_{2}$ adsorptiondesorption isotherm as well as to determine the pore size distribution. The curve sketched in Figure $8(a)$ is clearly offering desorption hysteresis of type-IV isotherm curve $[29,30]$ obtained under a relative pressure $\left(\mathrm{P} / \mathrm{P}_{\mathrm{o}}\right)$ of $0.1-1.0$. The characteristics of mesostructured materials can be well explained on the basis of sharp capillary condensation steps occurring between relative pressure intervals of 0.40-0.95. It also perceives mesopores irregularity in the product. The BJH pore size distribution is profiled in Figure 8(b). A sharp peak could be depicted in the beginning of distribution curve demonstrating an average pore diameter of $3.35 \mathrm{~nm}$. The pore volume and surface area of the particles in the sample was determined using Brunauer-Emmett-Teller (BET) analysis. Accordingly, owe to its plentiful range of pore diameter $(2-80 \mathrm{~nm})$, it can accumulate higher number of charge carriers, thus improving the electrolyte performance of the current specimen. Hence, it can offer its utilization in a wide collection of potential applications.

$\mathrm{CV}$ measurements were implemented to analyze the ongoing electrode reactions throughout the charge/discharge for $\beta-\mathrm{SnWO}_{4}$ nanostructures. The $\mathrm{CV}$ profile was mapped under various current cycles and a potential window of 0.01 to $3.0 \mathrm{~V}$ and is demonstrated in Figure 9(a). The composition is clearly describing the actuality of anodic/cathodic peaks. Similar current humps can be perceived from all the current cycles. During lithiation, three peaks can be depicted specifying multi-lithiation progression [21]. The reduction of $\beta-\mathrm{SnWO}_{4}$ to $\mathrm{Sn}$ and $\mathrm{W}$ was noticed from $1^{\text {st }}$ reduction peak appeared around $2.31 \mathrm{~V}$ as prescribed in Eq. 9. Another reduction peak 
occurred at $1.59 \mathrm{~V}$ justifying the $\mathrm{Sn}$-metal reaction in excess vicinity of $\mathrm{Li}+$ ions (alloying reaction) [31]. The following reaction can be perceived in Eq. 10. In addition, the W-metal reaction with LiSn and excessive $\mathrm{Li}+$ ions can be observed in Eq. 11 that is resulted from the existence of $3^{\text {rd }}$ reduction peak around $0.77 \mathrm{~V}$. The reverse of reduction known as oxidation also occurred. The anodic peak appeared around $0.53 \mathrm{~V}$ is attributed to the de-alloying of $\mathrm{Li}_{x} \mathrm{Sn}$ while the peak appeared at $2.40 \mathrm{~V}$ is identifying the oxidation of $\mathrm{Sn}$ and $\mathrm{W}$ to $\beta-\mathrm{SnWO}_{4}$. The probable electrochemical reactions are as follows [21];

$$
\begin{gathered}
\beta-\mathrm{SnWO}_{4}+x \mathrm{Li}^{+}+x \mathrm{e}^{-} \rightarrow \mathrm{Sn}+\mathrm{W}+x \mathrm{Li}_{2} \mathrm{O} \\
\mathrm{Sn}+\mathrm{Li}^{+}+\mathrm{e}^{-} \leftrightarrow \mathrm{LiSn} \\
\mathrm{LiSn}+\mathrm{W}+x \mathrm{Li}_{2} \mathrm{O} \leftrightarrow \mathrm{Sn}+\mathrm{WO}_{3}+x \mathrm{Li}^{+}+x \mathrm{e}^{-}+\mathrm{Li}_{2} \mathrm{O}
\end{gathered}
$$

The galvanometric charge/discharge (GCD) curves for $\beta-\mathrm{SnWO}_{4}$ at a scan rate of $0.1 \mathrm{C}$ and in the voltage range of $0.01-3.0 \mathrm{~V}$ and is sketched in Figure $9(\mathrm{~b})$. The $1^{\text {st }}$ cycle exhibited a discharge capacity of $1180 \mathrm{mAhg}^{-1}$ and $2^{\text {nd }}$ cycle displayed charge and discharge capacities of 608 $\mathrm{mAhg}^{-1}$ and $638 \mathrm{mAhg}^{-1}$, respectively. Theoretically, $\beta-\mathrm{SnWO}_{4}$ demonstrates a capacity of 850 $\mathrm{mAhg}^{-1}$ [32]. The excessive discharge capacity is mainly due to interfacial storage [33]. As the curves depict higher discharge capacity than charge capacity that can be attributable to the factors such as; electrolyte decomposition, unavoidable $\mathrm{SEI}$ formation and generation of $\mathrm{Li}_{2} \mathrm{O}$, owing to irreversible Li-ions interactions [34]. A decrease in charge/discharge capacities with an increase in current rate is representing an excellent ionic and electrical conductivity, and an exceptional rate capability.

The rate capability of $\beta-\mathrm{SnWO}_{4}$ was examined at numerous current rates $(0.1-3 \mathrm{C})$ and has been shown in Figure 9(c). A specific capacity of $54 \mathrm{mAhg}^{-1}$ was attained at a current rate of $3 \mathrm{C}$. Further, an excessive specific capacitance of $600 \mathrm{mAhg}^{-1}$ was noticeable when reverse current was 
brought at $0.1 \mathrm{C}$. The contemporary extreme electrochemical performance of $\beta-\mathrm{SnWO}_{4}$ is indicating highly stable electrode material towards energy storage applications.

The specific charge-discharge capacities and columbic efficiency of $\beta-\mathrm{SnWO}_{4}$ were performed at C/10 rate and is profiled in Figure 9(d). From graph, it is evident that almost constant and stabilized charge-discharge capacities of 105 and $58 \mathrm{mAhg}^{-1}$ were obtained. In addition, a coulombic efficiency of nearly $100 \%$ was professed.

\section{Conclusion}

$\beta-\mathrm{SnWO}_{4}$ nanoparticles were synthesized by microwave heat treatment method, facilitated by the reaction of $\mathrm{SnCl}_{2}$ and $\mathrm{H}_{2} \mathrm{WO}_{4}$, in the presence of tamarind seed powder. XRD analysis confirmed the crystalline nature of $\beta-\mathrm{SnWO}_{4}$ nanoparticles which was found to be cubic in nature. SEM analysis revealed the formation of $\beta-\mathrm{SnWO}_{4}$ stone like arbitrary and amalgamated nanoclusters with some traces of porosity. EDX analysis confirmed the existence of all constituent elements i.e., tin, oxygen and tungsten in the desired stoichiometric ratio. Spherical shaped particles were perceived by TEM analysis and an interlayer $d$-spacing was examined through HRTEM which was found to be $0.33 \mathrm{~nm}$, corresponding to (001) plane. The occurrences of bright rings in the pattern illustrated the highly crystallite nature of the sample. The peaks emerging in FTIR spectrum at about $609,768,851$ and $1443 \mathrm{~cm}^{-1}$ illuminated the stretching vibrations of $\mathrm{WO}_{6}^{-6}$ group, $\mathrm{W}-\mathrm{W}$ and $\mathrm{W}-\mathrm{O}-\mathrm{W}$ bridging bonds, $\mathrm{C}-\mathrm{C}$ or $\mathrm{C}-\mathrm{O}-\mathrm{C}$ bonds, respectively. The mesopores irregularity in the product was perceived by BJH analysis. A sharp peak as evident in the beginning of distribution curve, demonstrated an average pore diameter of $3.35 \mathrm{~nm}$. The CV profile was mapped under various current cycles which confirmed the composition by describing the actuality of anodic/cathodic peaks (multi-lithiation and de-lithiation process). The reduction peak appearing around $2.31,1.59$ and $0.77 \mathrm{~V}$, demonstrated the reduction of $\beta-\mathrm{SnWO}_{4}$ to $\mathrm{Sn}$ and $\mathrm{W}$, Sn-metal 
reaction and W-metal reaction, respectively. In GCD analysis, $1^{\text {st }}$ cycle exhibited a discharge capacity of $1180 \mathrm{mAhg}^{-1}$ and the $2^{\text {nd }}$ cycle displayed charge and discharge capacities of 608 and $638 \mathrm{mAhg}^{-1}$, respectively. Moreover, a decrease in charge/discharge capacities was observed with an increase in current rate which represented an excellent ionic and electrical conductivity and exceptional rate capability of about $600 \mathrm{mAhg}^{-1}$ at $0.1 \mathrm{C}$ (reverse current). In addition, it also exhibited $\sim 100 \%$ columbic efficiency, thus $\beta-\mathrm{SnWO}_{4}$ is highly favorable to be utilized as an electrode material for energy storage devices.

\section{Acknowledgement}

Authors thank the financial support from Kingdom of Saudi Arabia, Ministry of Education, Najran University, Promising Centre for Sensors and Electronic Devices (PCSED) sanction on 2019 (Ref. No: PCSED-021-18). Researchers Supporting Project number (RSP-2020/160), King Saud University, Saudi Arabia. Nagaraju Ganganagappa thank DST Nanomission (Project No. SR/NM/NS-1262/2013 (G), New Delhi, Govt. of India for financial support to carry out the research work.

Author Contributions: Conceptualization, Fahad A. Alharthi, Sumedha H N; Nagaraju Ganganagappa; Data curation, Mabkhoot A. Alsaiari; Shashank M; Formal analysis, Mohammed S. Jalalah; Funding acquisition, Fahad A. Alharthi Resources, Naushad Ahmad; Visualization, Jari S. Algethami, Vishwanth; Writing - original draft, Naushad Ahmad; Writing - review \& editing, Fahad A. Alharthi, Nagaraju Ganganagappa, Mabkhoot A. Alsaiari, Mohammed S. Jalalah, and Jari S. Algethami. 


\section{References}

[1] P.A. Shinde, S.C. Jun, Review on recent progress in the development of tungsten oxide based electrodes for electrochemical energy storage, ChemSusChem. 13(1) (2020) 11-38.

[2] X. Hu, W. Zhang, X. Liu, Y. Mei, Y. Huang, Nanostructured Mo-based electrode materials for electrochemical energy storage, Chem. Soc. Rev. 44(8) (2015) 2376-2404.

[3] N. Zhang, X. Xiao, H. Pang, Transition metal (Fe, Co, Ni) fluoride-based materials for electrochemical energy storage, Nanoscale Horiz. 4(1) (2019) 99-116.

[4] K. Borzutzki, J. Thienenkamp, M. Diehl, M. Winter, G. Brunklaus, Fluorinated polysulfonamide based single ion conducting room temperature applicable gel-type polymer electrolytes for lithium ion batteries, J. Mater. Chem. A, 7(1) (2019) 188-201.

[5] B. Gao, X. Li, K. Ding, C. Huang, Q. Li, P.K. Chu, K. Huo, Recent progress in nanostructured transition metal nitrides for advanced electrochemical energy storage, J. Mater. Chem. A, 7(1) (2019) 14-37.

[6] X. Wang, B. Li, D. Liu, H. Xiong, $\mathrm{ZnWO}_{4}$ nanocrystals/reduced graphene oxide hybrids: synthesis and their application for Li ion batteries, Sci. China Chem. 57(1) (2014) 122-126.

[7] P. Wang, H. Liu, Q. Tan, J. Yang, Ruthenium oxide-based nanocomposites with high specific surface area and improved capacitance as a supercapacitor, RSC Adv. 4(81) (2014) 42839-42845. [8] P.A. Shinde, V.C. Lokhande, T. Ji, C.D. Lokhande, Facile synthesis of hierarchical mesoporous weirds-like morphological $\mathrm{MnO}_{2}$ thin films on carbon cloth for high performance supercapacitor application, J. Colloid Interf. Sci. 498 (2017) 202-209.

[9] J. Zhang, J. Ding, C. Li, B. Li, D. Li, Z. Liu, Y. Liu, Fabrication of novel ternary threedimensional $\mathrm{RuO}_{2} /$ graphitic- $\mathrm{C}_{3} \mathrm{~N}_{4} @$ reduced graphene oxide aerogel composites for supercapacitors, ACS Sustain. Chem. Eng. 5(6) (2017) 4982-4991.

[10] K.N. Manukumar, B. Kishore, K. Manjunath, G. Nagaraju, Mesoporous $\mathrm{Ta}_{2} \mathrm{O}_{5}$ nanoparticles as an anode material for lithium ion battery and an efficient photocatalyst for hydrogen evolution, Int. J. Hydrogen Energ. 43(39) (2018) 18125-18135.

[11] B. Huang, X. Li, Y. Pei, S. Li, X. Cao, R.C. Masse, G. Cao, Novel carbon-encapsulated porous $\mathrm{SnO}_{2}$ anode for lithium-ion batteries with much improved cyclic stability, Small 12(14) (2016) 1945-1955. 
[12] H. Liu, W. Li, D. Shen, D. Zhao, G. Wang, Graphitic carbon conformal coating of mesoporous $\mathrm{TiO}_{2}$ hollow spheres for high-performance lithium ion battery anodes, J. Am. Chem. Soc. 137(40) (2015) 13161-13166.

[13] G. Zhu, W. Que, J. Zhang, P. Zhong, Photocatalytic activity of $\mathrm{SnWO}_{4}$ and $\mathrm{SnW}_{3} \mathrm{O}_{9}$ nanostructures prepared by a surfactant-assisted hydrothermal process, Mater. Sci. Eng. B, 176(18) (2011) 1448-1455.

[14] S.R. Ede, S. Kundu, Microwave synthesis of $\mathrm{SnWO}_{4}$ nanoassemblies on DNA scaffold: a novel material for high performance supercapacitor and as catalyst for butanol oxidation, ACS Sustain. Chem. Eng. 3(9) (2015) 2321-2336.

[15] J.L. Solis, V. Lantto, Gas-sensing properties of different $\alpha-\mathrm{SnWO}_{4}$-based thick films, Phys. Scripta, (1997) 281.

[16] S.R. Ede, S. Kundu, Microwave synthesis of $\mathrm{SnWO}_{4}$ nanoassemblies on DNA scaffold: a novel material for high performance supercapacitor and as catalyst for butanol oxidation, ACS Sustain. Chem. Eng. 3(9) (2015) 2321-2336.

[17] L. Warmuth, C. Feldmann, $\beta$-SnWO4 with morphology-controlled synthesis and facetdepending photocatalysis, ACS omega, 4(8) (2019) 13400-13407.

[18] I.S. Cho, C.H. Kwak, D.W. Kim, S. Lee, K.S. Hong, Photophysical, photoelectrochemical, and photocatalytic properties of novel SnWO4 oxide semiconductors with narrow band gaps, J. Phys. Chem. C, 113(24) (2009) 10647-10653.

[19] X. Wang, B. Li, D. Liu, H. Xiong, $\mathrm{ZnWO}_{4}$ nanocrystals/reduced graphene oxide hybrids: Synthesis and their application for Li ion batteries, Sci. China Chem. 57(1) (2014) 122-126.

[20] R. Huang, H. Ge, X. Lin, Y. Guo, R. Yuan, X. Fu, Z. Li, Facile one-pot preparation of $\alpha-$ $\mathrm{SnWO}_{4} /$ reduced graphene oxide (RGO) nanocomposite with improved visible light photocatalytic activity and anode performance for Li-ion batteries, RSC Adv. 3(4) (2013) 1235-1242.

[21] F.A. Alharthi, M.A. Alsaiari, M.S. Jalalah, M. Shashank, A.A. Alghamdi, J.S. Algethami, N. Ganganagappa, Combustion synthesis of $\beta$-SnWO4-rGO: Anode material for Li-ion battery and photocatalytic dye degradation, Ceram. Int. (2020).

[22] M.T. Ansar, A. Ali, G.M. Mustafa, F. Afzal, S. Ishaq, F. Kanwal, S. Atiq, Polypyrrole-based nanocomposites architecture as multifunctional material for futuristic energy storage applications, J. Alloy. Compd. (2020) 157341. 
[23] G.M. Mustafa, S. Atiq, S.K. Abbas, S. Riaz, S. Naseem, Tunable structural and electrical impedance properties of pyrochlores based $\mathrm{Nd}$ doped lanthanum zirconate nanoparticles for capacitive applications, Ceram. Int. 44(2) (2018) 2170-2177.

[24] K. Karthik, S. Dhanuskodi, C. Gobinath, S. Prabukumar, S. Sivaramakrishnan, Ultrasonicassisted CdO-MgO nanocomposite for multifunctional applications, Mater. Tech. 34(7) (2019) 403-414.

[25] A. Quader, G.M. Mustafa, S.K. Abbas, H. Ahmad, S. Riaz, S. Naseem, S. Atiq, Efficient energy storage and fast switching capabilities in Nd-substituted $\mathrm{La}_{2} \mathrm{Sn}_{2} \mathrm{O}_{7}$ pyrochlores. Chem. Eng. J. (2010) 125198.

[26] N.S. Pavithra, S.B. Patil, S.K. Kumar, F.A. Alharthi, G. Nagaraju, Facile synthesis of nanocrystalline $\beta$-SnWO 4 : as a photocatalyst, biosensor and anode for Li-ion battery, SN Appl. Sci. 1(9) (2019) 1123.

[27] K.M. Garadkar, L.A. Ghule, K.B. Sapnar, S.D. Dhole, A facile synthesis of $\mathrm{ZnWO}_{4}$ nanoparticles by microwave assisted technique and its application in photocatalysis, Mater. Res. Bull. 48 (2018) 1105-1109.

[28] L. Han, X. Zhou, L. Wan, Y. Deng, S. Zhan, Synthesis of $\mathrm{ZnFe}_{2} \mathrm{O}_{4}$ nanoplates by succinic acid-assisted hydrothermal route and their photocatalytic degradation of rhodamine B under visible light, J. Environ. Chem. Eng. 2(1) (2014) 123-130.

[29] S. Mani, V. Vediyappan, S.M. Chen, R. Madhu, V. Pitchaimani, J.Y. Chang, S.B. Liu, Hydrothermal synthesis of $\mathrm{NiWO}_{4}$ crystals for high performance non-enzymatic glucose biosensors, Sci. Rep. 6 (2016) 24128.

[30] S. Ding, J.S. Chen, X.W. Lou, One-dimensional hierarchical structures composed of novel metal oxide nanosheets on a carbon nanotube backbone and their lithium-storage properties, Adv. Funct. Mater. 21(21) (2011) 4120-4125.

[31] H.W. Shim, I.S. Cho, K.S. Hong, A.H. Lim, D.W. Kim, Wolframite-type ZnWO $\mathrm{Zn}_{4}$ nanorods as new anodes for Li-ion batteries, J. Phys. Chem. C, 115 (2011) 16228-16233.

[32] N.S. Pavithra, S.B. Patil, S.K. Kumar, F.A. Alharthi, G. Nagaraju, Facile synthesis of nanocrystalline $\beta-\mathrm{SnWO}_{4}$ : as a photocatalyst, biosensor and anode for Li-ion battery, SN Appl. Sci. 1 (2019) 1123. 
[33] S.B. Patil, B. Kishore, G. Nagaraju, J. Dupont, High capacity $\mathrm{MoO}_{3} / \mathrm{rGO}$ nanocomposite anode for lithium ion batteries: an intuition into the conversion mechanism of $\mathrm{MoO}_{3}$, New J. Chem. 42 (2018) 18569-18577.

[34] K.N. Manukumar, B. Kishore, K. Manjunath, G. Nagaraju, Mesoporous $\mathrm{Ta}_{2} \mathrm{O}_{5}$ nanoparticles as an anode material for lithium ion battery and an efficient photocatalyst for hydrogen evolution, Int. J. Hydrogen Energ. 43 (2018) 18125-18135. 


\section{Figure captions}

Figure 1 Schematic illustration of sample synthesis

Figure 2 (a) Indexed XRD pattern and (b) magnified image of certain peaks of $\beta-\mathrm{SnWO}_{4}$ nanoparticles

Figure 3 Williamson-Hall (W-H) plot of $\beta-\mathrm{SnWO}_{4}$ nanoparticles

Figure 4 Rietveld refined XRD pattern of $\beta-\mathrm{SnWO}_{4}$ nanostructures

Figure 5 (a-c) SEM images and (d) EDAX spectrum (inset: elemental composition) of $\beta$ - SnWO4 nanoparticles

Figure 6 (a-b) TEM, (c) HR-TEM and (d) SEAD pattern of $\beta$ - $\mathrm{SnWO}_{4}$ nanoparticles

Figure 7 FTIR spectrum of $\beta-\mathrm{SnWO}_{4}$ nanoparticles

Figure 8 (a) BJH adsorption-desorption isotherm and (b) pore size distribution of $\beta-\mathrm{SnWO}_{4}$ nanostructures

Figure 9 (a) Cyclic voltammogram, (b) Galvanostatic charge-discharge, (c) Rate capability at different current density and (d) Cycling performance and columbic efficiency of $\beta-\mathrm{SnWO}_{4}$ nanoparticles 


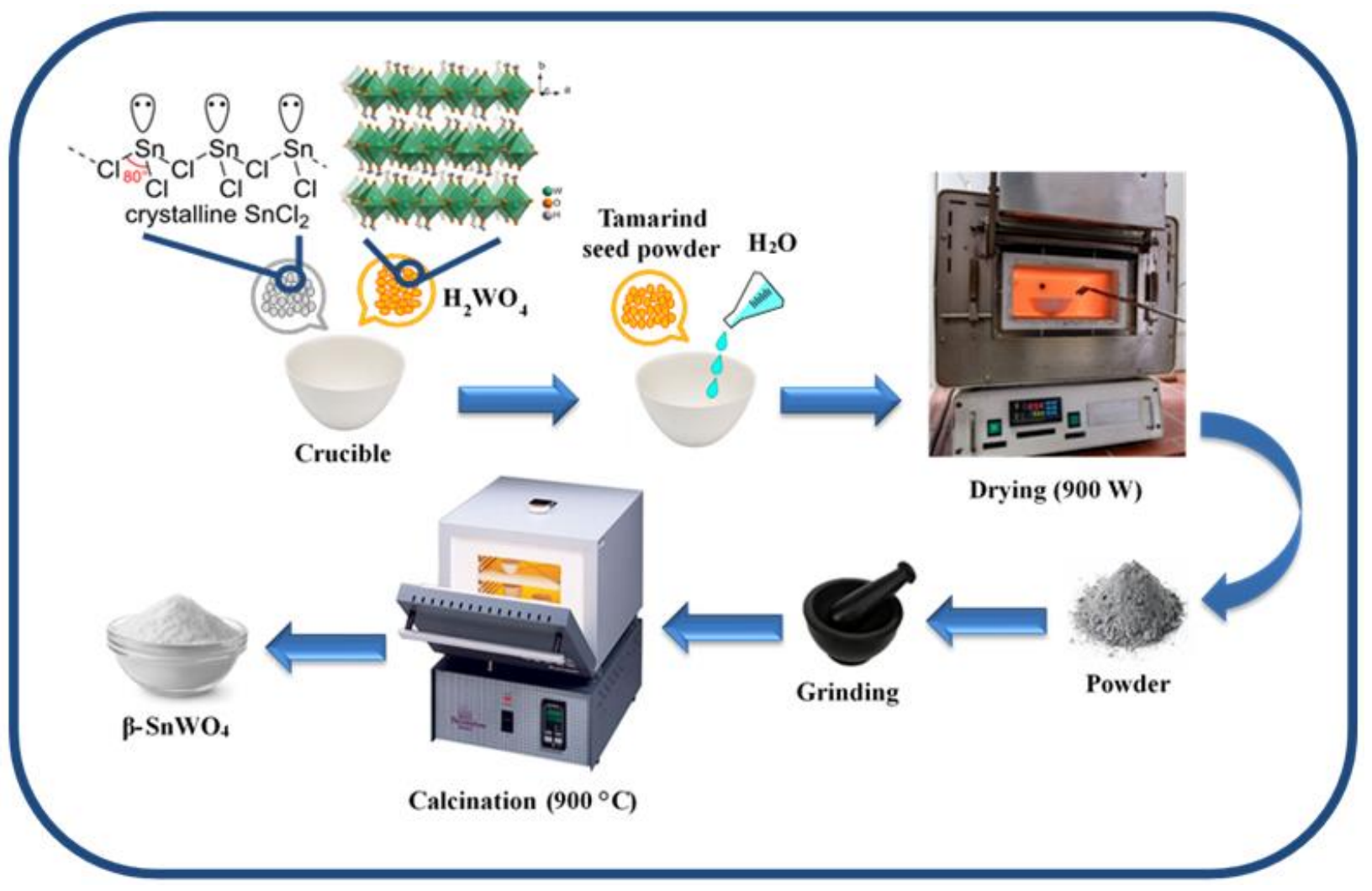

Figure 1 Schematic illustration of sample synthesis 

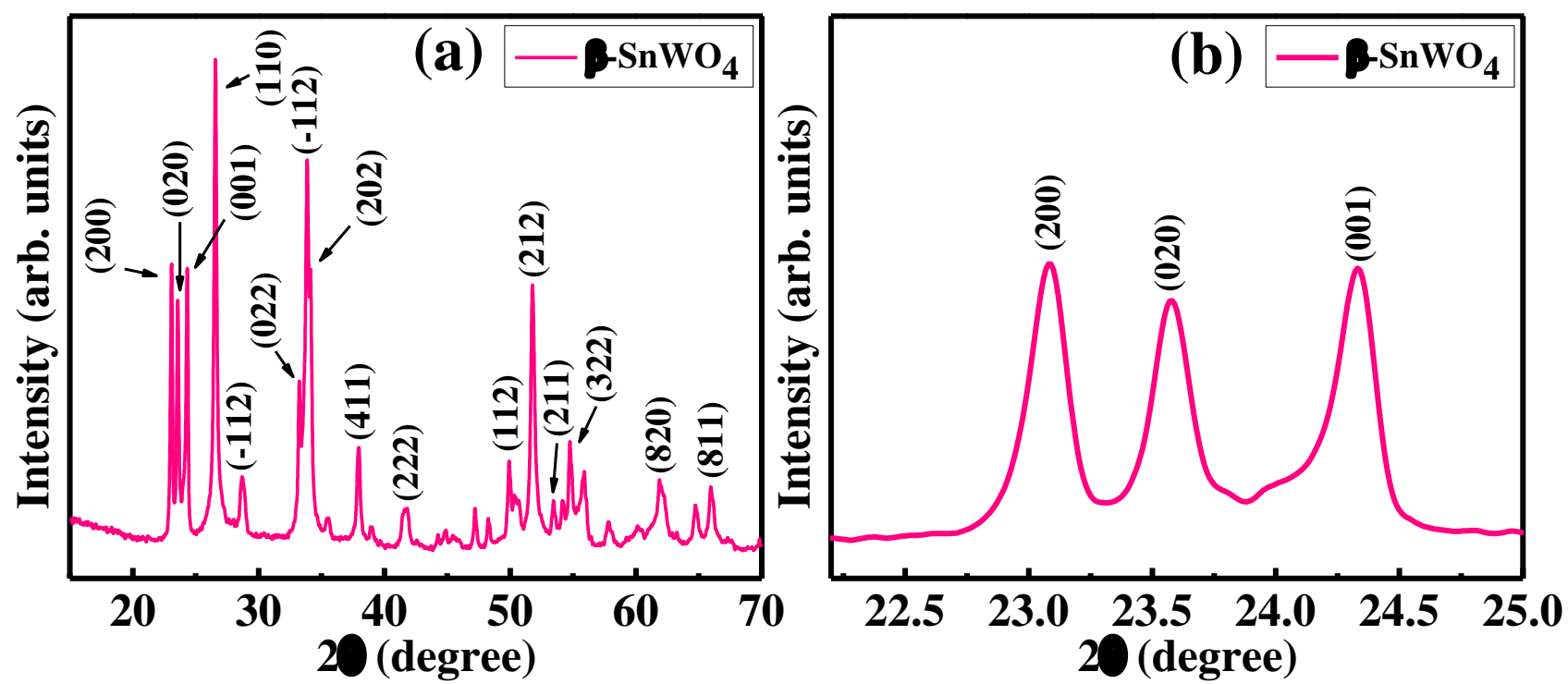

Figure 2 (a) Indexed XRD pattern and (b) magnified image of certain peaks of $\beta-\mathrm{SnWO}_{4}$ nanoparticles 


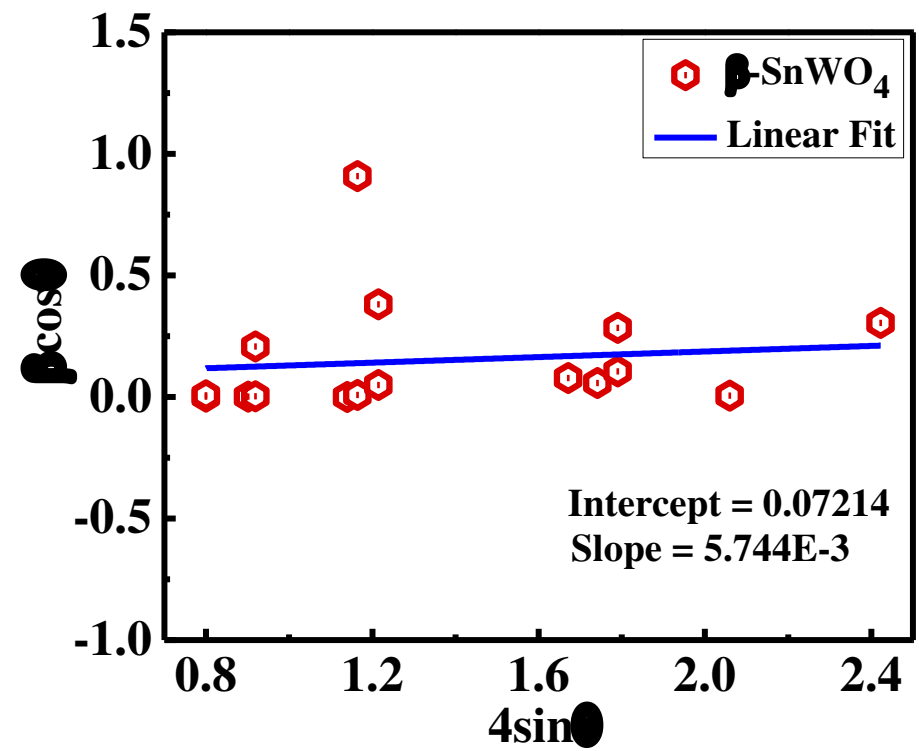

Figure 3 Williamson-Hall (W-H) plot of $\beta-\mathrm{SnWO}_{4}$ nanoparticles 

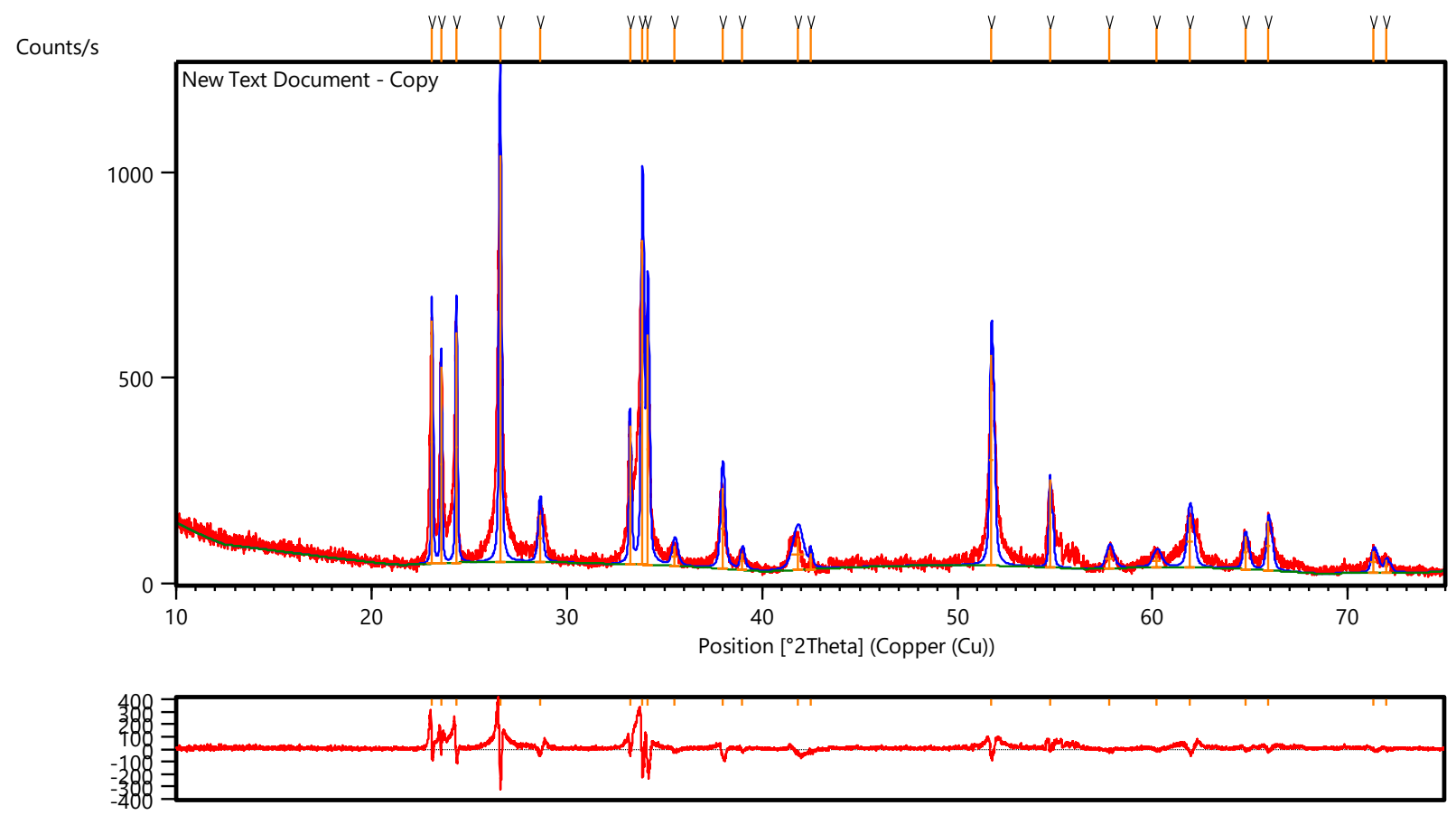

Figure 4 Rietveld refined XRD pattern of $\beta-\mathrm{SnWO}_{4}$ nanostructures 


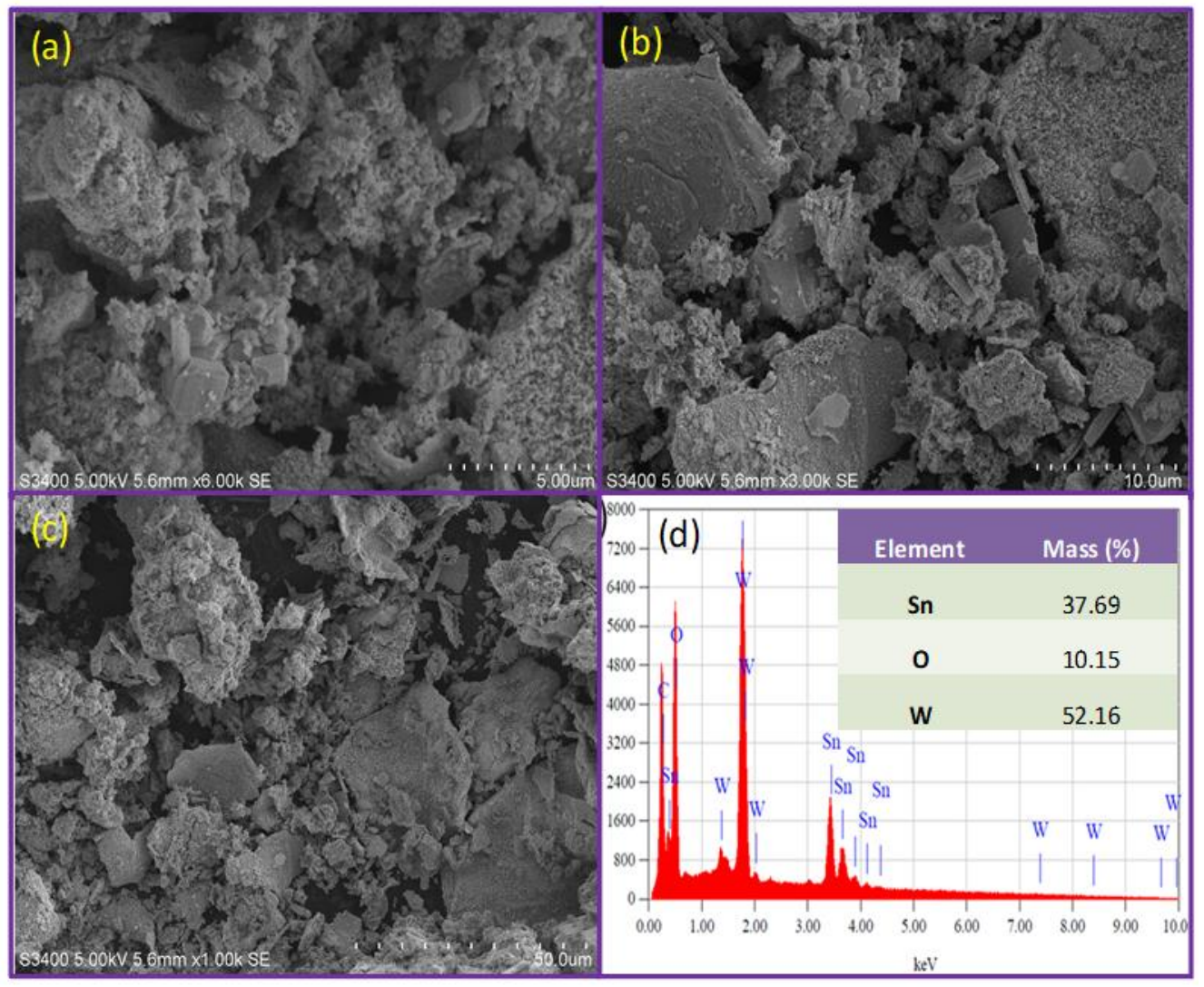

Figure 5 (a-c) SEM images and (d) EDAX spectrum (inset: elemental composition) of $\beta$ - $\mathrm{SnWO}_{4}$ nanoparticles 


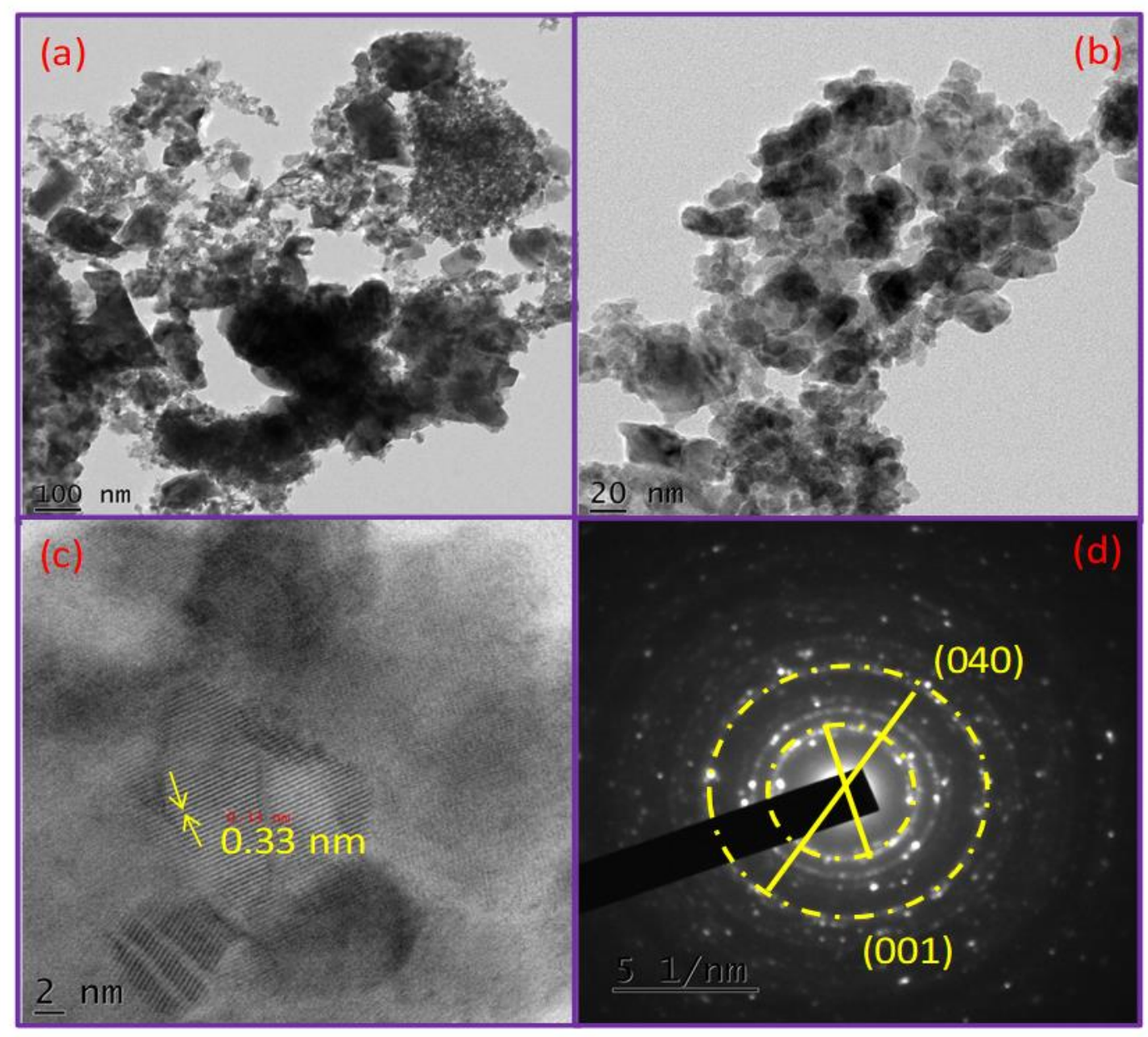

Figure 6 (a-b) TEM, (c) HR-TEM and (d) SEAD pattern of $\beta$ - SnWO4 nanoparticles 


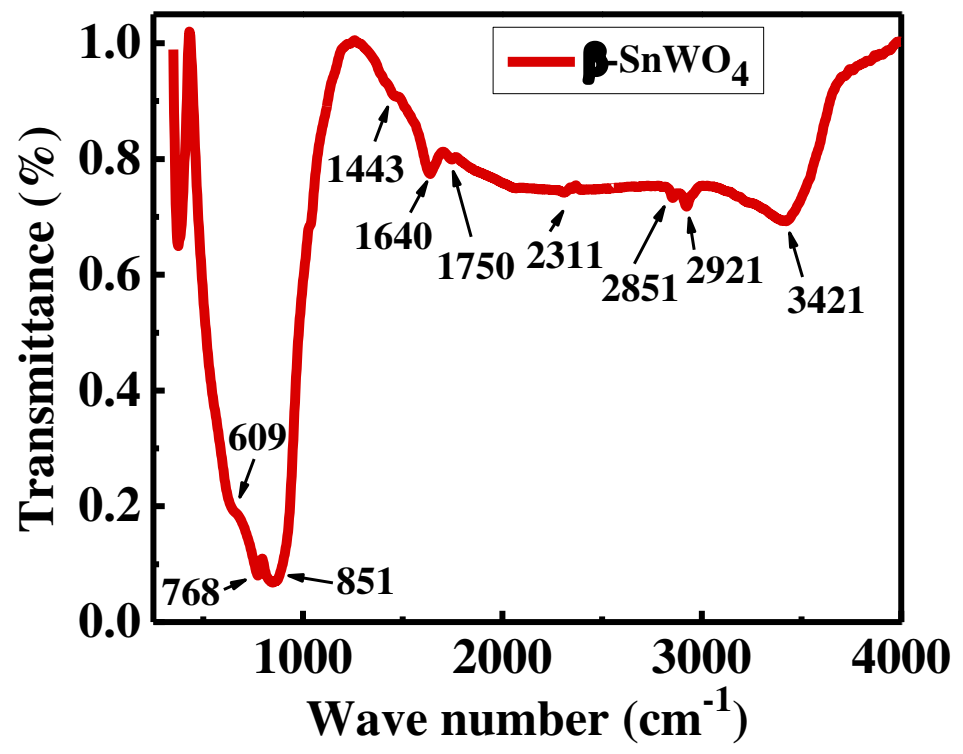

Figure 7 FTIR spectrum of $\beta-\mathrm{SnWO}_{4}$ nanoparticles 

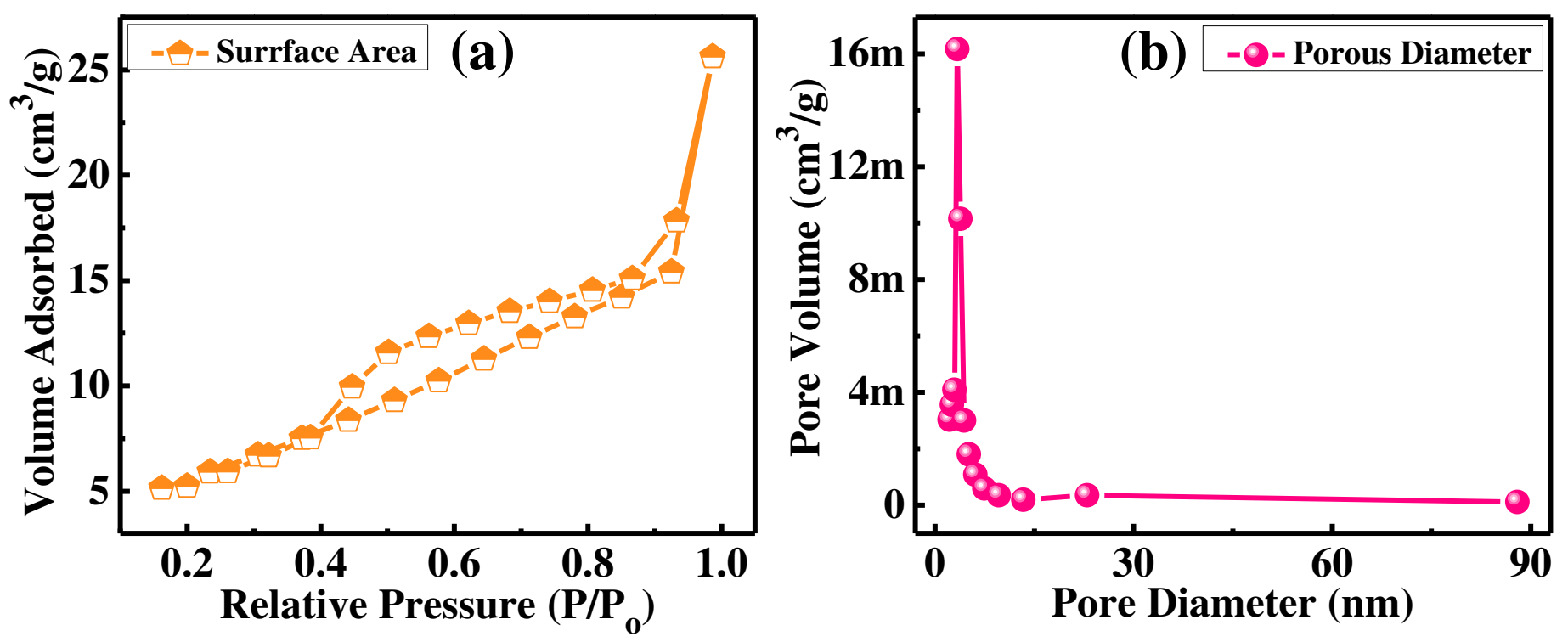

Figure 8 (a) BJH adsorption-desorption isotherm and (b) pore size distribution of $\beta-\mathrm{SnWO}_{4}$ nanostructures 

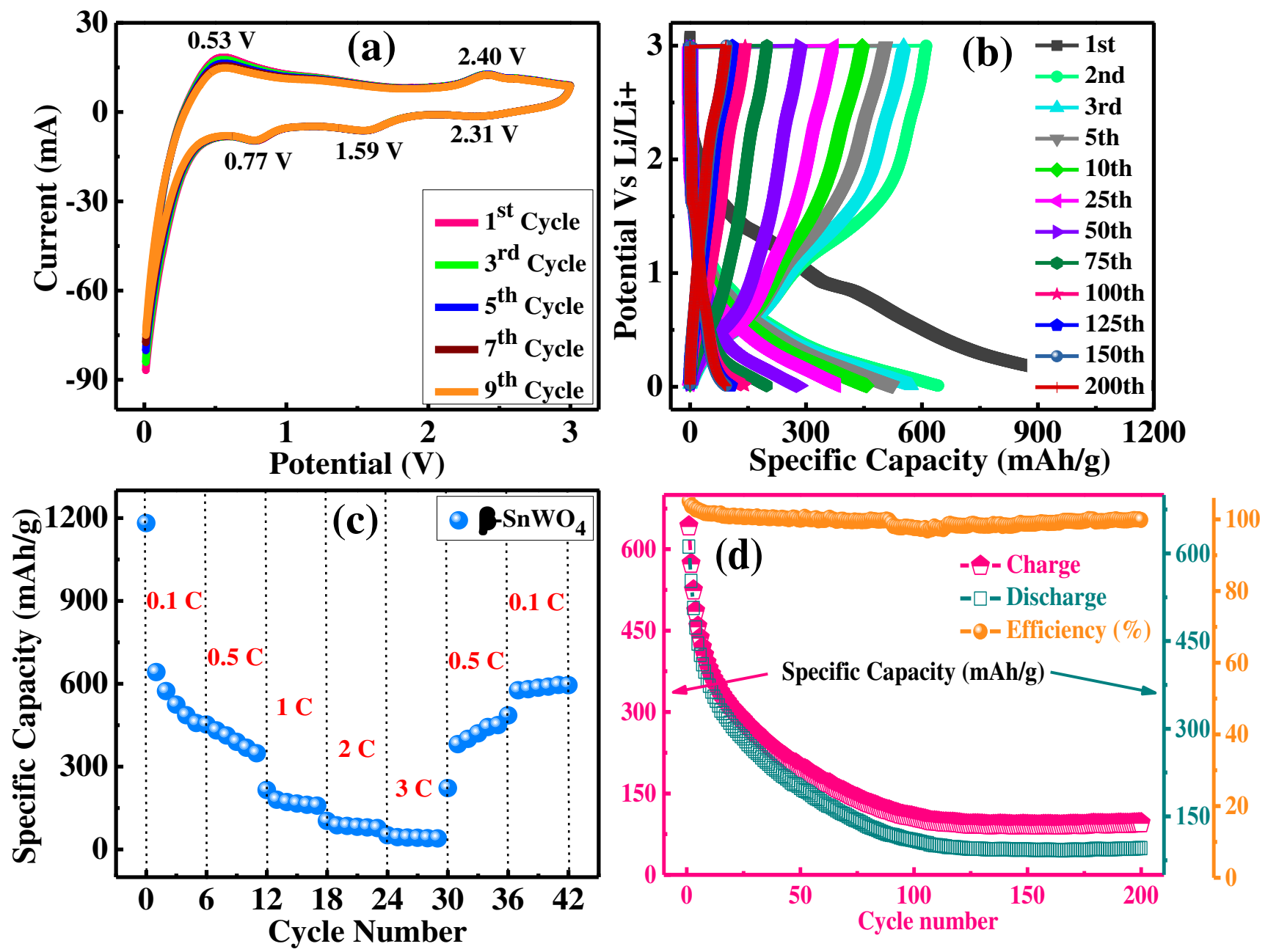

Figure 9 (a) Cyclic voltammogram, (b) Galvanostatic charge-discharge, (c) Rate capability at different current density and (d) Cycling performance and columbic efficiency of $\beta$ - $\mathrm{SnWO}_{4}$ nanoparticles 
Figures

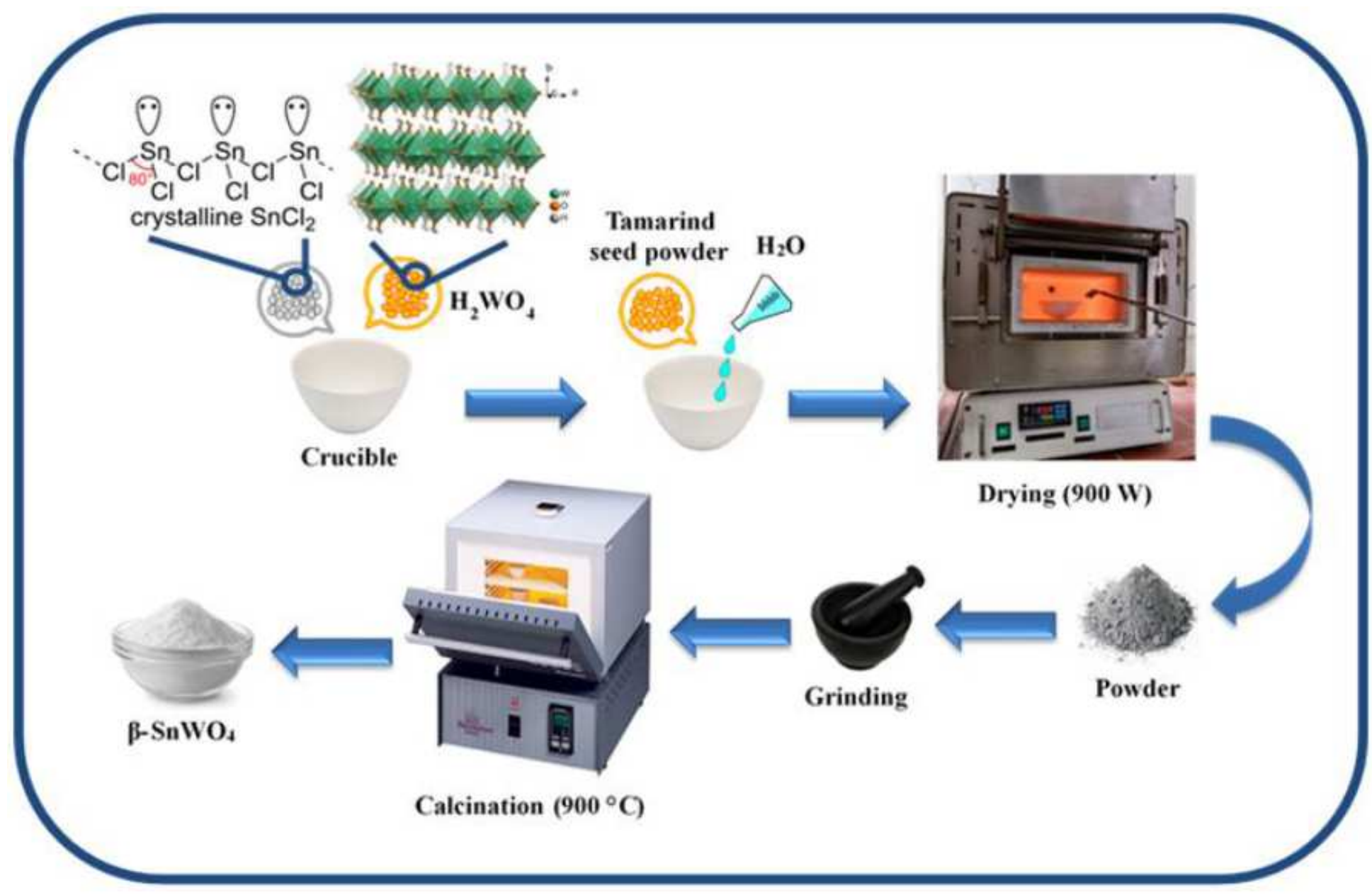

Figure 1

Schematic illustration of sample synthesis
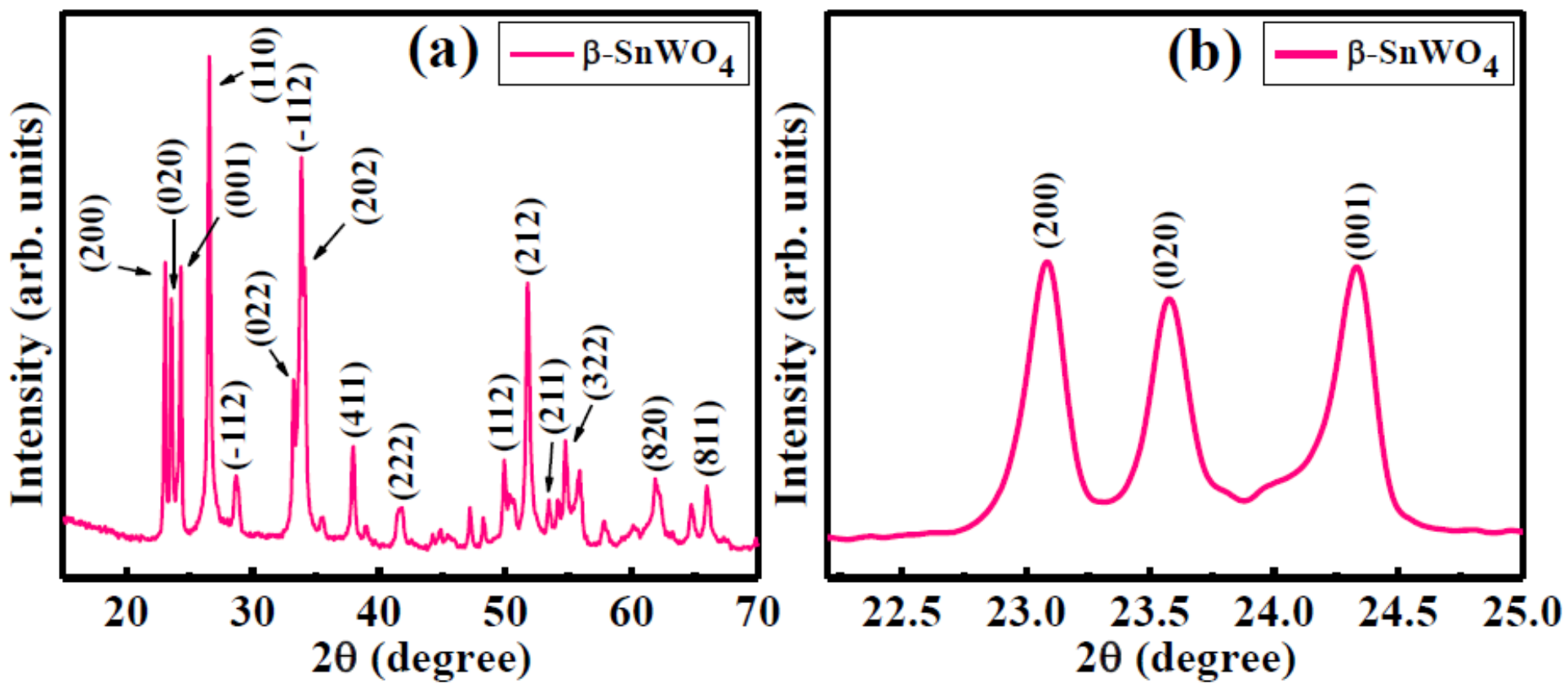
Figure 2

(a) Indexed XRD pattern and (b) magnified image of certain peaks of $\beta$-SnWO4 nanoparticles

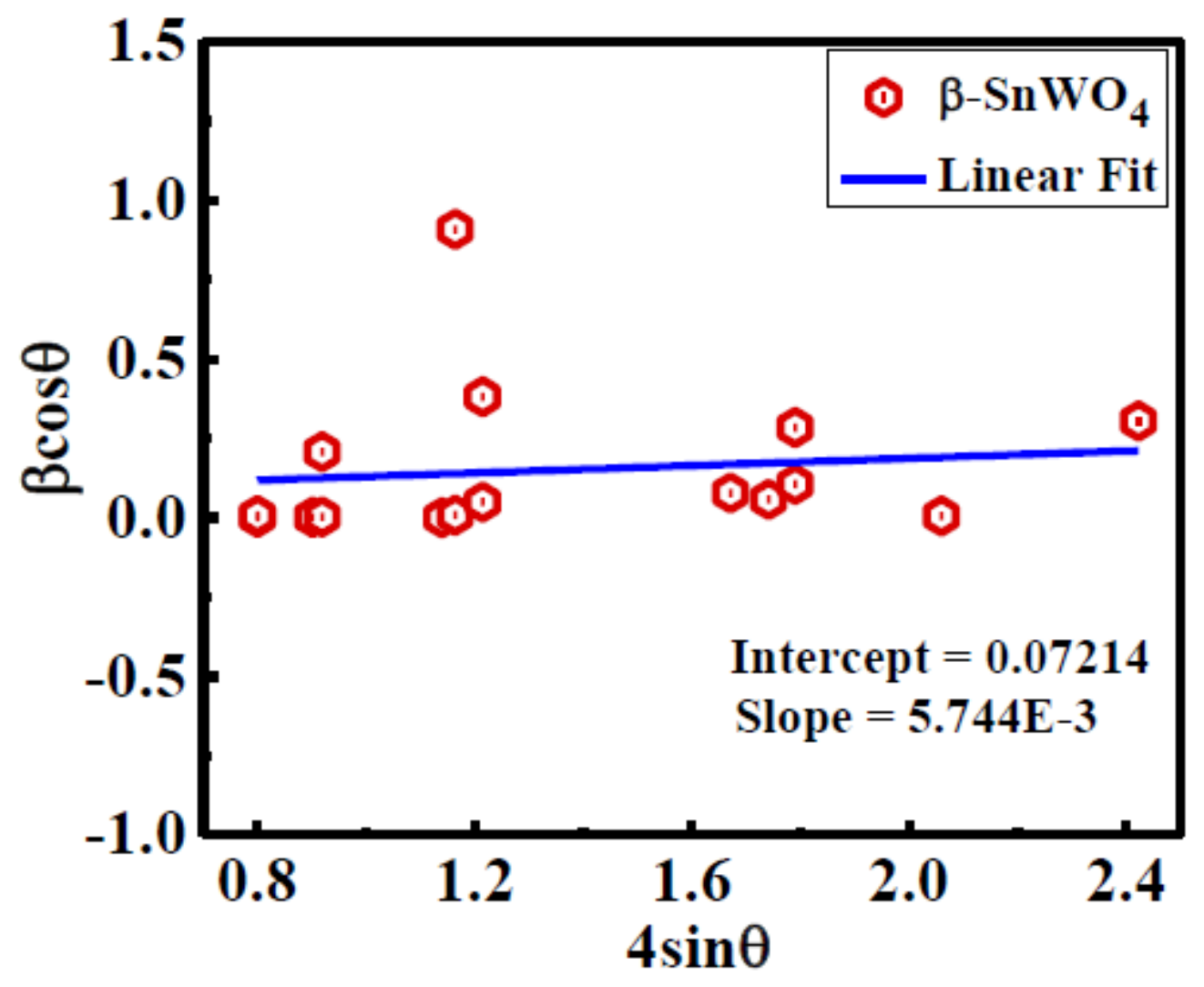

Figure 3

Williamson-Hall (W-H) plot of $\beta$-SnWO4 nanoparticles 

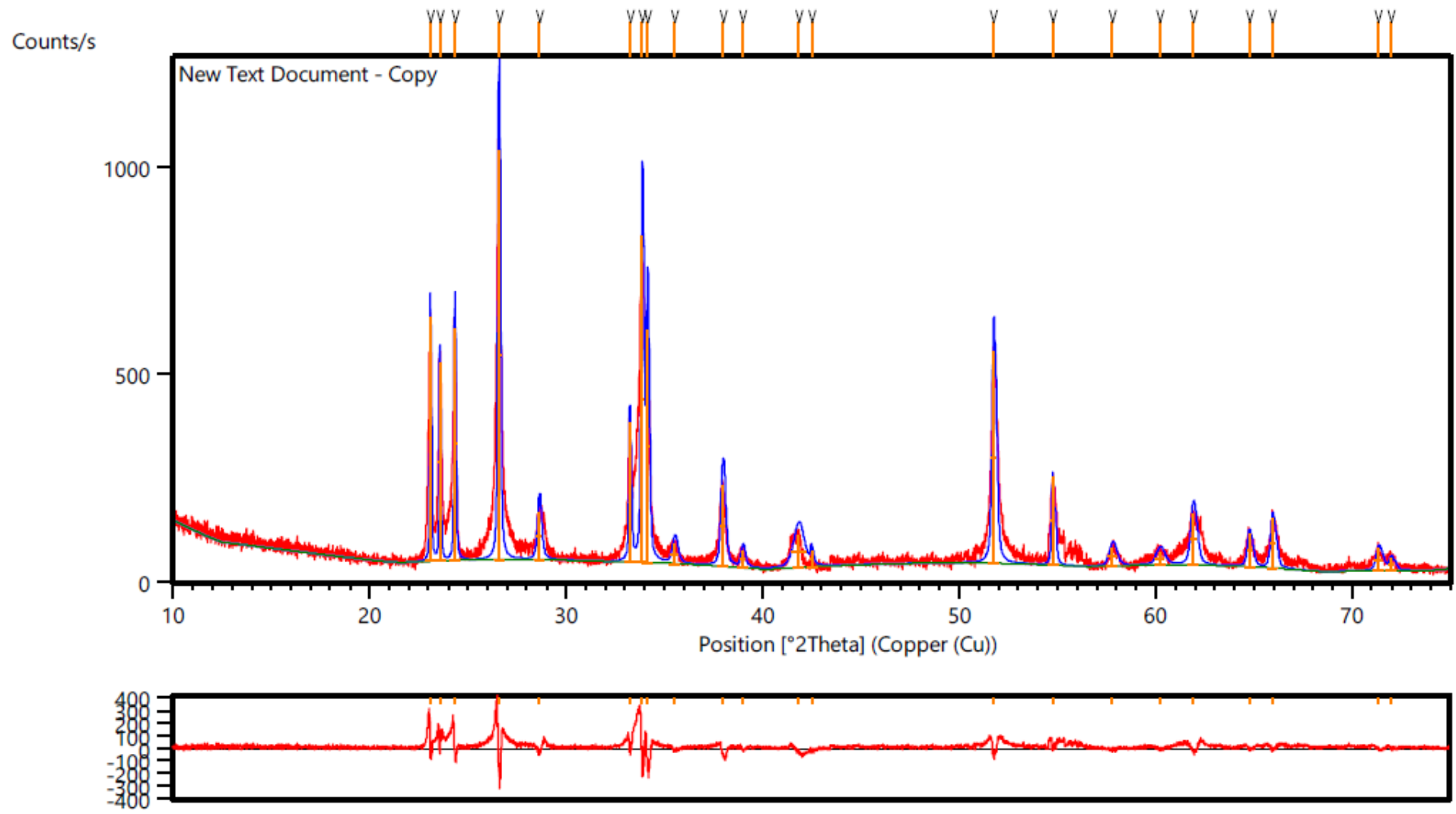

Figure 4

Rietveld refined XRD pattern of $\beta$-SnWO4 nanostructures 


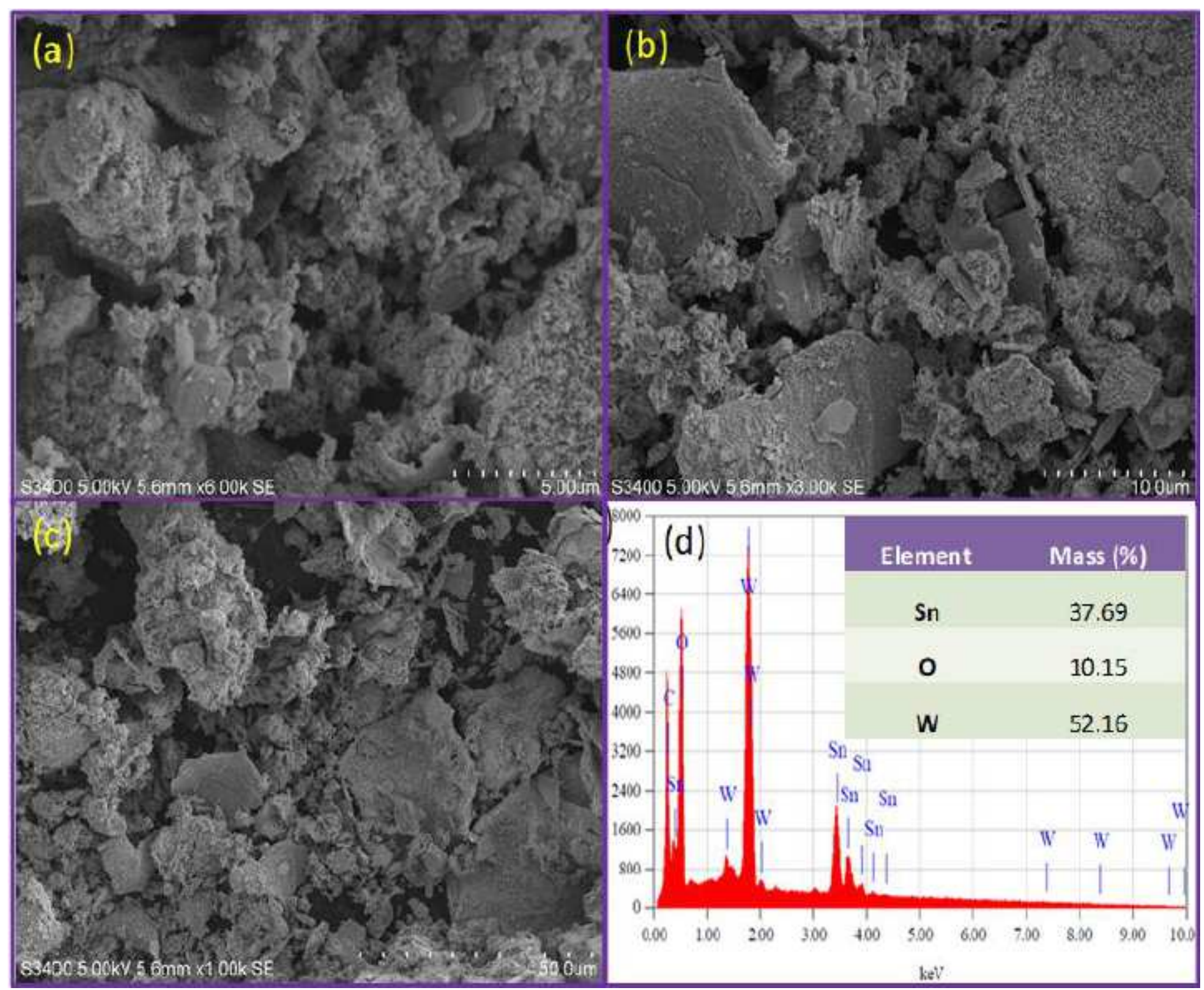

Figure 5

(a-c) SEM images and (d) EDAX spectrum (inset: elemental composition) of $\beta$ - SnWO4 nanoparticles 


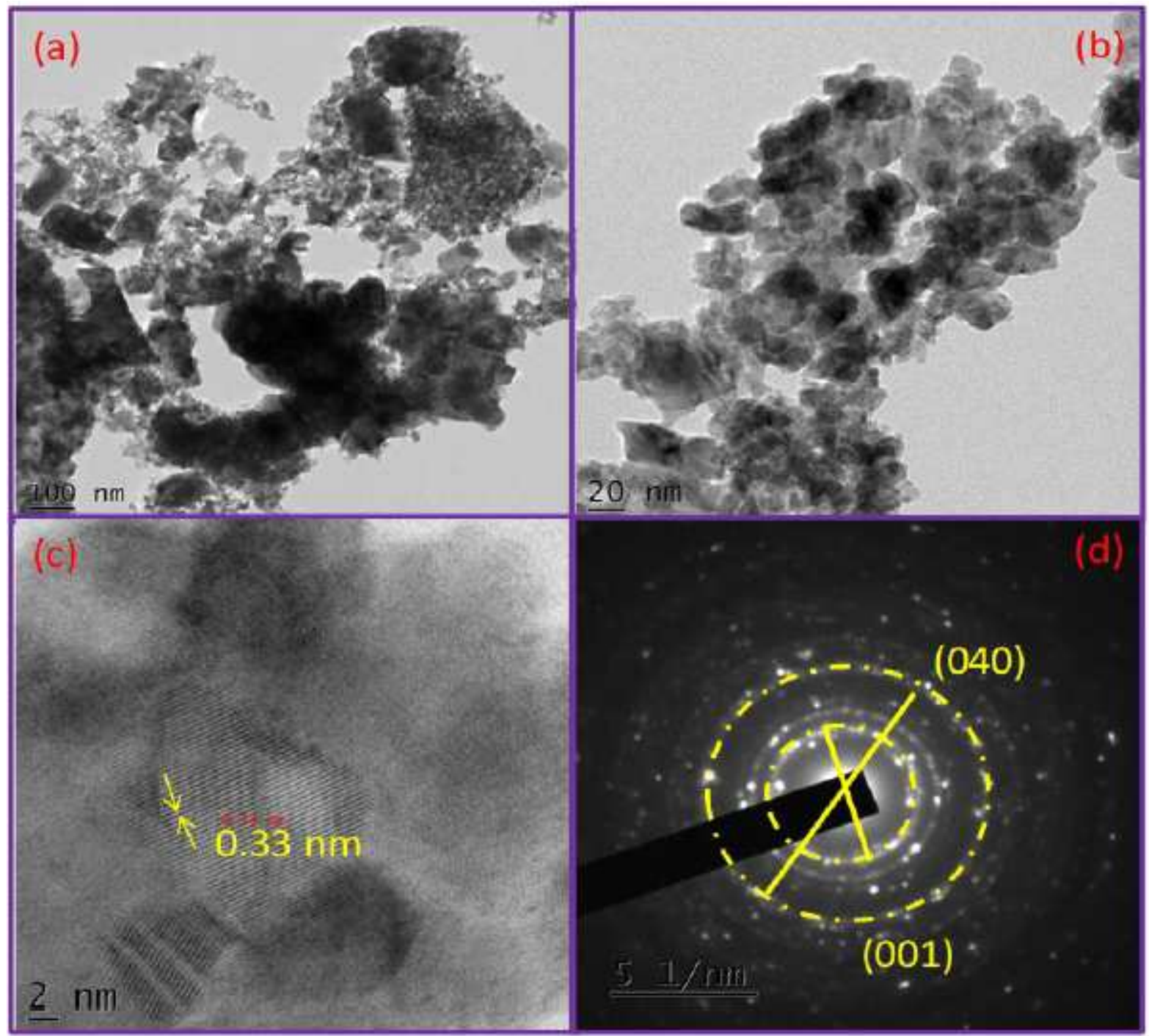

Figure 6

(a-b) TEM, (c) HR-TEM and (d) SEAD pattern of $\beta$ - SnWO4 nanoparticles 


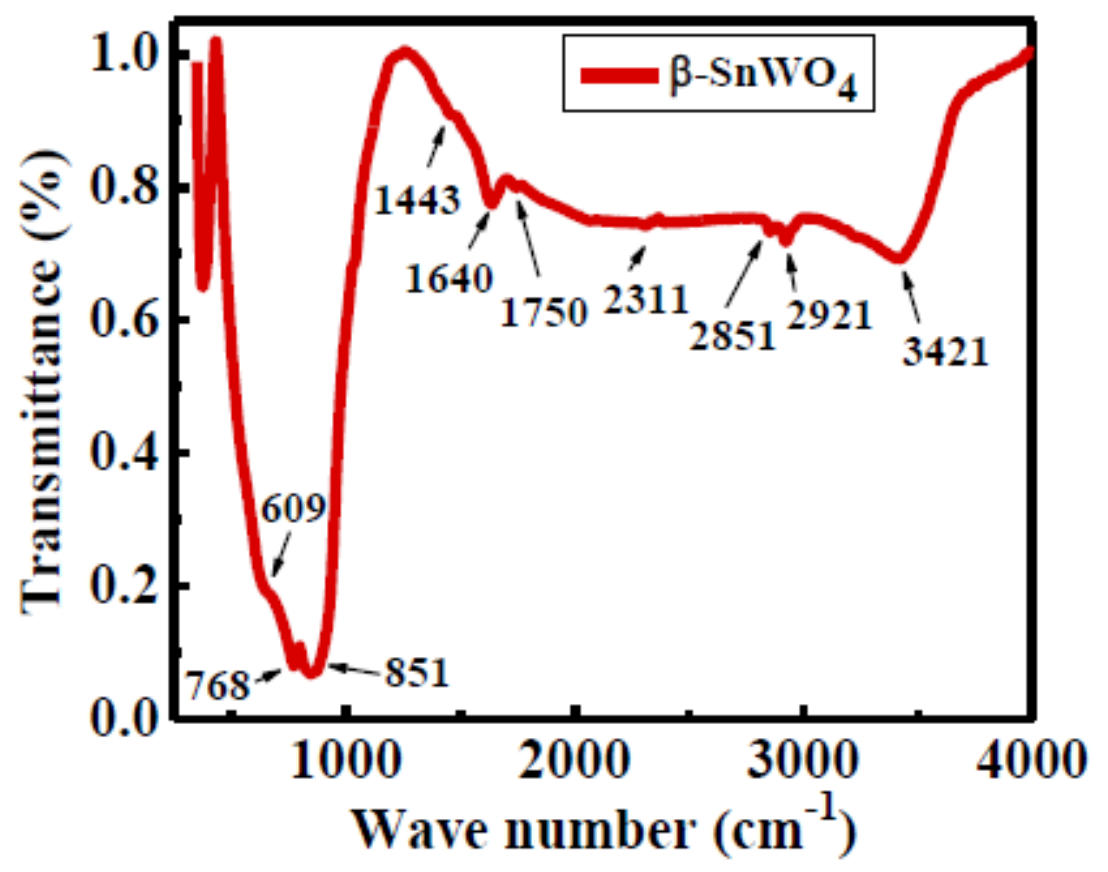

Figure 7

FTIR spectrum of $\beta$-SnWO4 nanoparticles
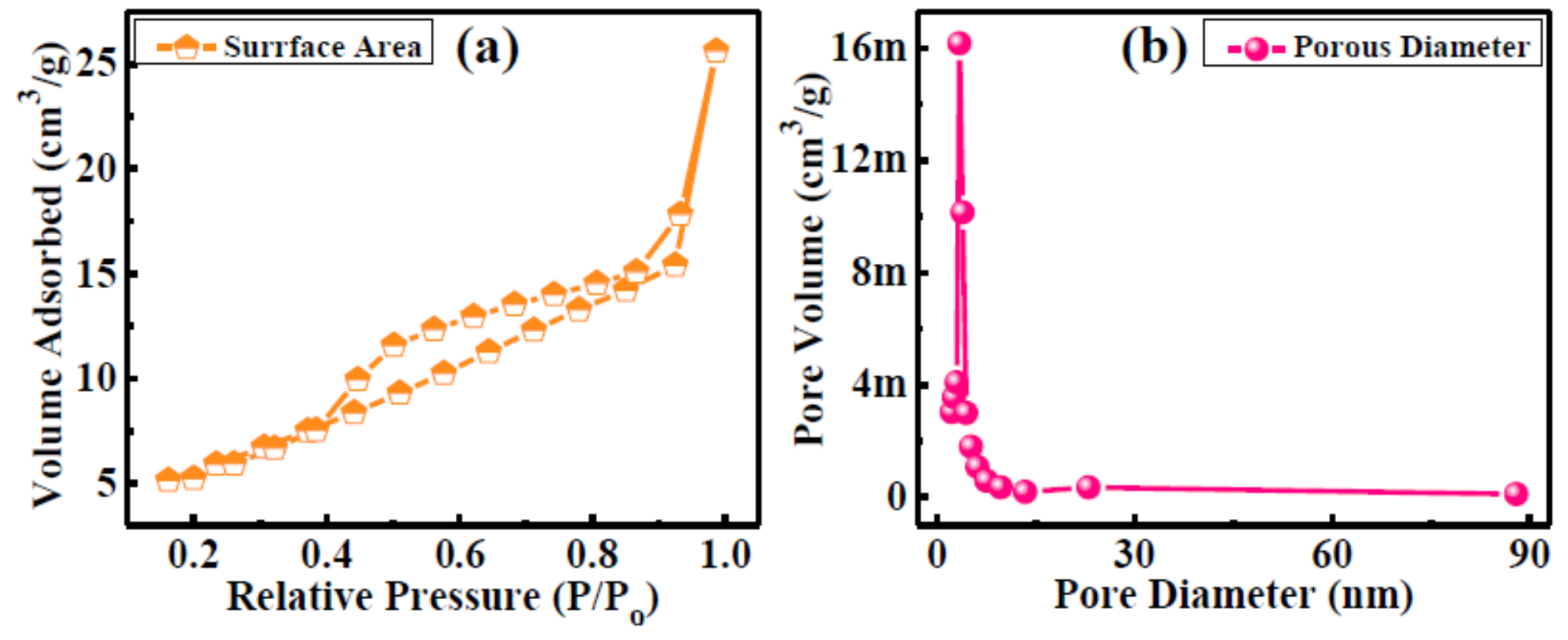

Figure 8

(a) BJH adsorption-desorption isotherm and (b) pore size distribution of $\beta$-SnWO4 nanostructures 

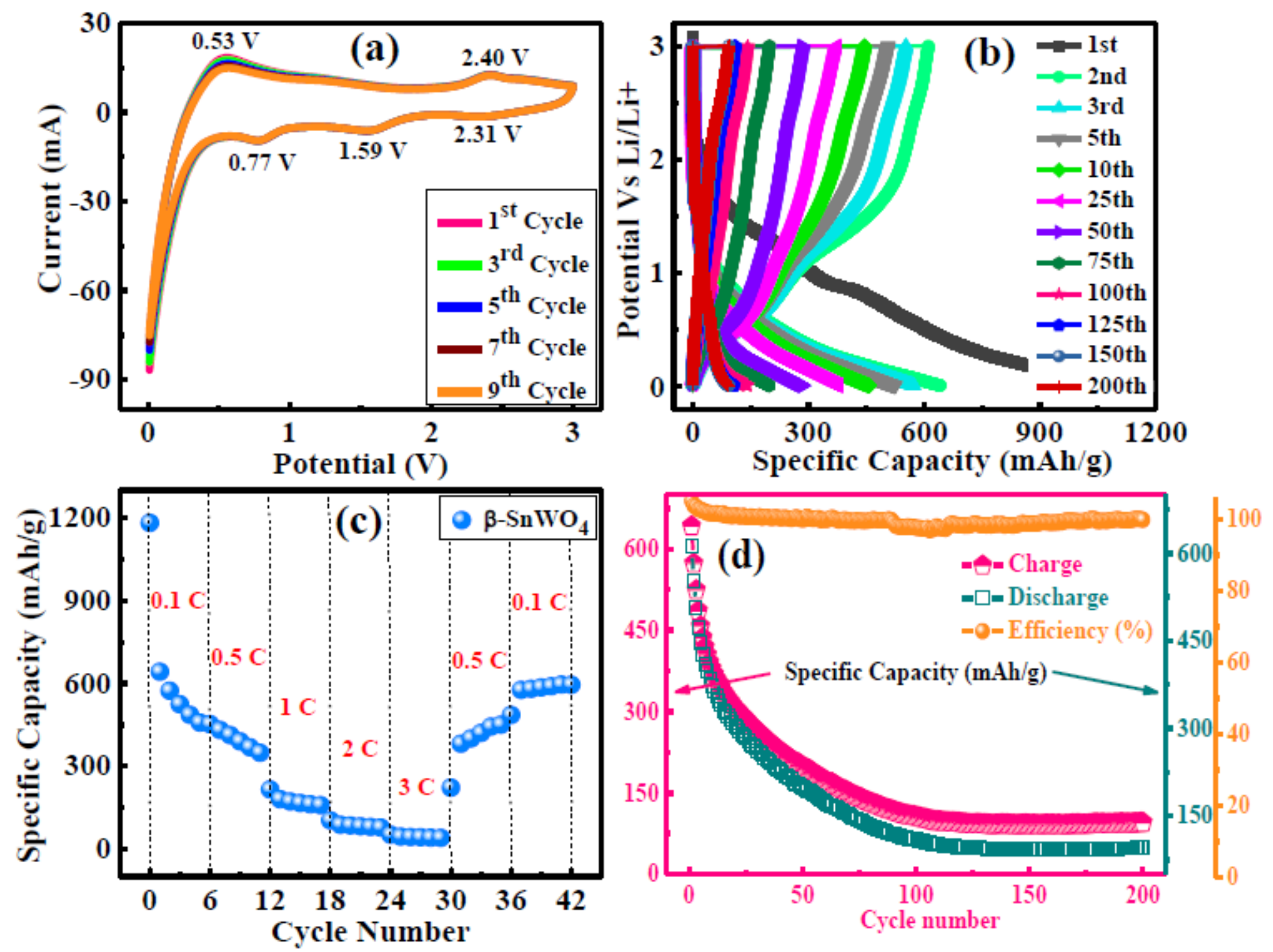

Figure 9

(a) Cyclic voltammogram, (b) Galvanostatic charge-discharge, (c) Rate capability at different current density and (d) Cycling performance and columbic efficiency of $\beta$-SnWO4 nanoparticles

\section{Supplementary Files}

This is a list of supplementary files associated with this preprint. Click to download.

- Table1.docx 